\title{
Philosophical reflection of childhood as projecting the "adult" world
}

\author{
Ekaterina Tikhomirova ${ }^{1}$ \\ 1 Don State Technical University, Department of philosophy and world religions, \\ 344000 Rostov-on-Don, Russian Federation
}

\begin{abstract}
Annotation. In the article the author presents the analysis of philosophical reflection of the phenomenon of childhood from antiquity to the present day. In connection with the "adult-child" reveals the theme of identity culture, the true person, the person as much in one. The study of the history of philosophical understanding of childhood revealed contradictions in the description of the essence of the dialogue between the adult and child Self, the problems of educational projects. The author explains how the dialogue is the formulation of the adult personality as a "teacher" ("educator") - the carrier of cultural norms and values and the design of the future personality in the child. The specificity of algorithms, methods of construction and representation of the Self always depends on the specifics of the history of culture. The author offers a way to solve the modern contradictions of "education" through the construction of the actual cultural dynamics of the communicative model "adult - child". This new model of dialogue should take into account psychophysiological aspects, historical and cultural, and non-historical, transcendental concepts when creating projects of the Mature Self in the child (with appropriate role behavior).
\end{abstract}

\section{Introduction}

The phenomenon of childhood has always aroused great interest of scientists of different directions. One angle for its study were natural physiological studies, the otherwere philosophical reflections, in which the problem of childhood was raised from ontological, epistemological, anthropological, existential, religious, moral and historical and cultural positions. The third point of reference, designated not so long ago (at the turn of the XIX-XX centuries), was a number of psychological theories, referring to the peculiarities of mental processes of the young individual. In the modernity, the problem of childhood has entered the political, legal, economic field, causing the emergence of many regulations that define the rights and duties of children, as well as the rights and duties of adults towards children. Philosophical reflection on culture today is also not left aside from the study of the phenomenon of childhood in the dynamics of culture, its essence, features, specifics of formation, as the concept and its specific contents.

What is the reason for such interest and breadth of views on the phenomenon of childhood? What makes a person invariably turn to the topic of childhood in certain areas of science? Answering these questions, considering all sorts of theories and concepts, directly or indirectly, affecting the theme of the little Self, we find lacunae of knowledge, which are directions to the definition of the essence and properties of the human principle, the ideas that affect the nature of philosophical reflection. The problems of childhood research inextricably interact with the philosophy and theory of culture, with their tasks of determining the essence of the subject of culture, the study of cultural identity, the 
processes of socialization and inculturation. The study of childhood helps to determine the main subjects of research maturity of the subject of culture, to clarify the nature, quality and degree of interaction between man and culture.

\section{Results and discussion}

All researchers who almost always baffled by description of the phenomenon of childhood. At what point can the individual be considered a person, an active principle; when certain factors (nature, God, the Other, society, culture) "begin" and "finish" to have a formative influence on the child? Is it possible to consider him (the child) as a subject or for natural reasons (as determining his dependence on adults) he can only be an individual, an individual of the animal world? The answers to these questions revealed the concept of dialogue as a way of knowing the essence of the subject.

Interaction of a child and an adult - a dialogue in which there is a multi-level representation of themselves to Other by all participants of communication. First, an adult who enters the drama of communication as an "educator", a "teacher" - a carrier of family, religious, ethical, aesthetic, scientific and other cultural values-presents himself to Other. An adult is a subject of a specific paradigm of culture that marks the boundaries of a wider cultural dialogue - subcultures of children and adults. Secondly, being Other, the adult in the dialogue overcomes time boundaries, referring to the child as to his past, the model of himself, the little Self, thereby marking the boundaries of epochs in internal communication-between a young and a adult person. Thirdly, in respect of adult-child presentation reveals himself to his future, because the child is an adult futuristic Self, which will be adult in a universal sense, objectively, and, respectively, to carry out subject-subject of cultural dialogue. In this "play" of cognition of oneself, one's past, present and future, many masks-projects of Self are born, which act as algorithms of communication and activity, become behavioral stereotypes of "fathers" and "children". The specificity of these algorithms, methods of presentation of the Self always depends on the specifics of the history of culture, as the adult world in the course of time formulated expectations and requests addressed to the child, based on the dominants of their culture and specific cultural products.

The child, entering into a dialogue with an adult, gets the opportunity to take part in the same intersubjective "masquerade" - to feel Other. First, the little Self is aware of dependence and limitation due to physiological factors: in comparison of abilities, the child is always different. Second, the child gets an idea of the world of Self, which he can enter, using the proposed adult algorithms. Participation in the dialogue, thus, on the part of the child is always a choice of values, behavioral norms that already exist, are given by the adult world and dominate the child's self. The role of the child is determined only by the choice of the meanings of culture known to the adult at a particular stage of history.

Thus, in seeking the essence of oneself, the adult world turns to the child. Philosophical reflection from the beginning included in its search the study of the mechanisms of such a dialogue. Initially, these ways of knowing the essence of the subject were presented through educational concepts. Starting from the study of the "big"- Mature as the core of the subject's personality, philosophical thought from the first stages of reflection began to consider the child as a prototype of an adult who can and should be prepared, transformed into an existence in culture. That is, the child was believed by the ancient philosophers, was way Pygmalion (activity, patience and love) to invest in adult life. With small differences, ancient philosophers believed the modeling of the future adult as the education of a citizen (citizenship was conceived as a cultural dominant). The result was supposed to be obtained with the help of sports, science and art with the child - in inextricable connection with the development of mind and body. 
One of the first who paid attention to childhood was Plato ("State", "Laws"), who believed that the education of children - is the preparation of future citizens of the policy. An ideal state will be created only if ideal citizens are "created", which should be prepared. And this education, according to Plato, was to be determined by physical activities (sports and dancing), reading, forming in the child the concept of good and virtue. Thus, Plato closely connected Self with the state system, which had to take care of future subjects for its reproduction and optimization. That is, the concept of the policy was determinant of the selection of children's behavioral patterns, for the subsequent updating in role behavior activities of citizens of the Polis. Aristotle added to Plato's system of teaching music (aesthetics and its specific content contributed, as did Aristotle, create a free sage, an aristocrat of the spirit) and the family as model state, thus noting the relationship of the child with the parents as a first experience (for Aristotle moral, affecting other relationships) collisions little Self with the Other, and the importance of the implications of this experience: "As a man is born, and is born from an animal - animal, and from good parents can occur only good offspring. Nature often strives for this, but cannot achieve it" ("Politics"). Parents, according to Aristotle, had to prepare the child for school-a place to study the unified state-useful knowledge. That is, Aristotle as well as Plato, linked the formation of man with the state system.

Among the Roman philosophy that appealed to children, we can note Cicero and his treatise "on duties", created in the genre of appeal to the son (whose education Cicero, indeed, engaged himself). In the text, the philosopher gives recommendations to the young man, which can be reduced to the principle of non-resistance to nature, which created man reasonable and, therefore, ready for education. This transformation (education) is aimed at teaching all kinds of Sciences, acquaintance with poetry, oratorical skills, is aimed at improving the "divine mind" given by nature. Cicero saw the little man as a finished model that needed to be brought to a certain quality.

The philosophical thought of the middle ages replaced the ancient natural understanding of the individual, as a creation for education in harmony of body and mind, on the "pedagogical" concept of religion character. The education of man was now determined by devotion to the soul, as the light of truth in everyone, which must be sought out and supplemented by perfection in the Sciences for moral growth (Augustine Aurelius "Confession", "About the city of God"). No one else talked about training new members for the state. Political, social aspect for quite a long time was excluded from the view on the young Self now everybody was equal and not equal before the law of the state, and before the law of God, which, being the value of culture, defined the boundaries of human and content of the basic relationships Self to Self, Self to World (Universe), Self to Other. Only one true Self, without a project, was possible - the soul, whose absolute had to be sought out and purified from sin by study and penance.

The Renaissance led philosophical views of the child as a" creation for education " anthropocentric way - through the vision of the individual as the center of the world, Creator and conqueror, and not as a creature of "God", modestly standing between the large-scale realities of the mythological and religious stage of reflection. The conqueror of the world was seen by the revivalists not always optimistically, but with a set of negative human qualities that must be eradicated. Vittorino del Feltre proposed to humanize the upbringing of the child through an appeal to his individual inclinations and abilities, which were supposed to develop sports, Sciences, aesthetically - music lessons. In his school "house joy" - not enforced corporal punishment, in the groundwork pedagogical practice was marked by game. Unfortunately his treatises de Feltre left, and information about his principles of attitude to childhood are in the memories of students. Tommaso Campanella, in his utopian work "The city of the sun", also paid attention to the formation of a citizen of an ideal state. Contrast to the ancient views on the personality of the Campanella made 
practical, realistic approach to education and skills through visual examples, games, and unobtrusive nature, professions, etc. the Main core of education for the philosopher saw the state, not the family he's from the process excluded. Thus, in the civic group and for the civic group at Campanella it was supposed to become from a young person to a large one.

New age in the basis of development of the person and the world laid the naturalscientific reasons. Rene Descartes, calling man a machine, tried to explain the formation of the Self by the influence of the laws of nature as a gradual development, the progress of everything around. Curbing the natural passions, doubt in this sense, the subordination of the mind that is able to eradicate evil, ignorance and lead to freedom, to the moral personality is the ideal. Children are deluded beings who are in the field of sensual prejudices. The only method that can lead a person to the top, Descartes saw science classes. Empiricist John Locke called the little man a "tabula rasa" which becomes an inner experience by feeling the world around it. His concept of education is extremely pragmatic: everything a person does should be useful in life. Children must learn self-contemplation, self-control, to be able to hear their minds. The ideal of such development is a "gentleman" - reasonable, moral, strong-willed, subordinating everything-both spirit and body, pragmatics ("Thoughts on education"). Thus, the transformation of the" pure " child's Self was associated with utilitarian foresight. For the first time we find not a "state" but a "sociality" that weaves the individual into itself, defining for itself a model of the self.

The philosophy of J.-J. Rousseau has a special place in the concepts of personality formation of the modern paradigm of culture. Rousseau believed that man must be cultivated, as well as plants, to get good fruit. All that is not given to the child initiallystrength, help, reason - it is necessary to instill educating. These qualities should be formed without contradiction the nature sometimes when you are creating extreme conditions on the hardening, hardship, etc. Child in the course of education should see the example of parents, as the family - form dictating content. The study of science should be begun only when the mind of the child is capable of not acquiring delusions. Thus, Rousseau's modeling was based on the synthesis of the natural and "soft power" of the mind, where the best variations of personality were found.

The German classical philosophy, for example Kant, saw in the child not the become subject, and far from the truth, limited in opportunities to reach it. Kant proposed the concept of moral education, according to his Central idea of the categorical imperative, as a condition for overcoming the animal state, a condition for becoming human. To teach children, thought Kant, we must patiently transforming a child's idea to develop the moral inclinations of the soul self (parent) as an example, to point to the maxims of good deeds ("Religion within the limits of the mind. G. Hegel, the first of the philosophers, connected the formation of the subject with culture, linking the meaning of education with history: the child must be prepared for the life of a citizen with free will in a free society. An important role in the formation of personality Hegel assigned to motherhood, which should serve as a conductor of sensual acceptance of morality. Thus, German philosophy defined the classical approach to the vision of the child as an unformed subject, a little adult, whose development is determined by the peculiarities of culture and historical process, and, accordingly, has an impact on the further development of society.

On the eve of the cultural crisis of the turn of XIX - XX centuries appeared views on the educational concepts of the future members of society. Now it is in this perspective socio - cultural-offered to reflect on the nature of childhood. K. Marx, arguing about history as the history of the class struggle, the connection of culture with the formation of economic formations, transposed this vision to the young Self, which was proposed to be torn out of the bourgeois paws, by the method of destroying these paws ("Manifesto of the Communist party"). The family, the school, as Marx rightly believed, is under pressure from the ruling class, because education is not free, natural. So, in the end of the New age, 
there was political-economic understanding of childhood. Again, adult historical and cultural labels were thrown on the concept of the child.

The singer of the crisis F. Nietzsche Zarathustra's words refers to the theme of childhood-in the child he sees the beginning of freedom, a new game. Only the Nietzschean child is an adult, a Mature personality. According to Nietzsche, the stages of formation Self undergo three stages: immersion in the experience of others and acquisition of knowledge the period of labour of a camel; a denial of someone else's experience and opinions - the period of a lion; and then in man a child is born - the free, unbound by rules. That is, the child is a pure truth, to which everything goes, and not a «tabula rasa» on which everything is written. And classical education is a heavy burden that must be borne in order to understand where to apply criticism, for the sake of freedom.

Entangled in the causes of the crisis of culture, Western philosophy decided to look for a way out, after all, in the subject, not in use, like Marx, is not "stupid" system of religious values that make a person dependent and unfree, was considered by Nietzsche, etc. Only now the philosophical view shifts from the problems of education as a way to alter the young Self to adult, need the state/society/history/culture in the study of the world by Self and its components. In them, as it seemed, lie the causes of destabilization of the external and internal world. In order to understand the reasons for this interpretation, we must pay attention to the cultural and historical context preceding this reflection. By the end of the nineteenth century definitively casual "preppy" glance at the child, as of an heir, the heir, the bearer of family values, in which for itself it is necessary to invest every possible effort. At this time there industry of childhood EN masse begin to produce toys, books, clothing. Man, realizing that the child is he, begins to make sacrifices to him, as a deity on whom the future depends. This trend, combined with a sense of crisis, gave impetus to the consideration of psycho- and physiological elements of the child-"idol". At first glance, suddenly, but in fact not, people began to try to understand children's problems, to choose the best teachers for children, to write books, to create games (and now "educational"), to lead to psychoanalysts. Then, this "fanaticism" was due, in addition to the above tangible reasons for the inheritance of the adult Self? The man was frightened. He was afraid of the abyss that began to open under his feet - the collapse of the foundations of culture, previously seemed unshakable. Looking for the causes of the cultural crisis, the subject turned to the inner world of the child, "accusing" him of his cultural problems. The resulting course of psychoanalysis was designed to detect the symptoms of the internal crisis of the adult individual in the child, to stop the destabilization of the internal space of the subject at an early stage - in childhood. Psychoanalysis outlined the field in which you can try to find some aspects of destruction. The founder of psychoanalysis Z. Freud, explaining the essence of the person through the interaction of the personality triad Ego Alter Ego - Id, put the problematic emphasis on their formation during childhood, as well as the leading forces of this formation - the death drive and sexual satisfaction. That is, an adult, being close to each stage of development, can have a beneficial (knowing the possible risks) or negative impact on the formation of a healthy personality. Thus, Freud started a whole range of philosophical and nearly philosophy directions, linking the transformation Self and culture, not educational or educational processes, and psycho- and physiological processes. Jung, developing original ideas of Freud, wrote about the resolution of emotional conflicts through constraint pressure adults libido, which actually is the source of development thinking. Later, Jung believed already that children need to see children, not young adults that anything is possible, but something is impossible. Only with such an approach can the harmonious formation of the subject - the formation of wholeness as self in the Union of elements (anima, animus, shadow, person, self).

G. Tarde made a contribution to the sociological direction of thinking about childhood, linking development with the success of socialization, communication, mediated by a 
bundle of "teacher-student", necessary for the assimilation of social norms and requests. T. Parsons associated development with society, but built his concept taking into account the psychoanalytic heritage: the mechanisms of tension and conflict, as he believed, provoke the subject to engage in dialogue with a significant Other tools of knowledge, adaptation and protection, which as a result allow to "absorb" cultural values. So, in the concepts concerning problems of cultural identification of the subject, self-knowledge, the cultural value of society, but not the state, God or scientific knowledge became a system-forming factor.

From psychological theories began to repel many philosophical trends of the early XX century. Michel Foucault (with whom the historian of everyday life F. Aries agrees in his work "the Child and family life under the old order", giving an epistemological meaning to "childhood") develops the concept of power, which determines the nature of the development of the cultural stage. Power ensures the effectiveness of the education of bodies, exercises control over the body, but not as a subject (Foucault, this concept is generally denied; man is an epistem, a set of relations in the discourse of specific epochs; I. e., "adult" - "child" -, too, epistem, which is changing from era to era, mediated by desire to gain power, create from child mask-construct "adult"), but as over some substrate, cultural harvesting. Power, as a force, forms disciplinary obedience. Foucault believes that modern power (postmodern era) is increasingly becoming biological in nature, as it affects all stages of life of the body - from birth (childhood) to death (compulsory medicine, education, work, etc.). And any communication for Foucault appears as a struggle of different forces - dominant and marginal, the purpose of which is to bring the blank to the norm (also epistemological). Deleuze is excited by the return to the child's state, not as communication with any particular little Self, but as a return to his own sensations-"un enfant quelconque", not yet mediated by alien experiences and feelings. Reality differs from perceptions from history. In reality, man acquires a variety of opposite contents: people-animals, men-women (and Vice versa), children - adults (and Vice versa). For Deleuze, the unconscious is a factory for the production of delusional images-ideas about the world, time, history, the Other.

\section{Conclusions}

Thus, for philosophical reflection, "childhood" and "child" turned out to be projects for the introduction of culturally determined sets of "adult" norms required for the selfdetermination of a Mature subject. The problem of self-determination began to appear almost insoluble in the conditions of cultural crisis (and destruction, erosion of values). Among the permanent collapse of the traditional "paradigms", "epistem", "systems of cultural values" the individual is hard to consider what you need to "teach" the child as the future itself.

Philosophical and cultural reflection of the phenomenon of childhood indicated the fact: it was difficult for a person to understand himself as a Friend, even using a convenient small model, giving her his "educational" projects (in learning, play, literature, everyday current practices). "Child care", positioned by today's culture is an ideologeme, and a variety of concepts of "development" for the "optimal" transformation of the child's Self pseudo-work of the become subject, behind which are hidden, in fact, adult shame and failures of self-knowledge.

These positions of philosophical reflection on the problems of childhood, as well as the positions of other humanitarian directions show that the subject of modern culture needs a fundamentally new communicative model "adult-child" - without mechanically changing combinations of "persons". This new model of dialogue should take into account psychoand physiological aspects, historical and cultural, and non-historical, transcendental concepts when creating projects of the Mature Self in the child (with appropriate role 
behavior). Until then, the subject's "childhood" will be a territory of masks, mechanistically and falsely actualized through the values of "education", "learning" and "development" transmitted by the adult world. Until this happens, "childhood" and "child" will remain uncomfortable categories for both philosophical reflection and cultural studies.

\section{References}

1. A. Losev Essays of ancient symbolism and mythology (Moscow, 1993)

2. O. Strelnik Myth and myth-making as elements of the communicative space of modern culture Questions of philosophy, 7, 75-83 (2018)

3. T. Parsons, R. Bales Family: Socialization and interaction process (1998) 